\title{
Model-based management (MBM): a vital prerequisite for organizational viability
}

\author{
Markus Schwaninger \\ University of St Gallen, St Gallen, Switzerland
}

\begin{abstract}
Purpose - The purpose of this paper is to introduce and conceptualize the topic of Model-based management (MBM) in organizations.

Design/methodology/approach - The relevance of different types of models for management is elaborated, and a research agenda for this new topic is proposed.

Findings - An analysis of the concept, role and function of models in the context of management and organization, as well as an outline for a new understanding of both the concept and role of models for management, grounded in system science is found.

Practical implications - Ultimately, MBM can enhance the intelligence, adaptiveness and viability of organizations of any kind: private, public, non-profit, large or small.

Originality/value - Taking models as the pivot of a research project on general management is unconventional. The gain promised by such an innovative scope derives from its high potential: both theory and practice can benefit from the envisaged research. Theoretically speaking, advances in management and organization science can be achieved, while on the practical side, the insights gained will caution managers and leaders against succumbing to the traps of complexity, while radically improving their managerial effectiveness.
\end{abstract}

Keywords General management, Modelling, Management effectiveness, Organizational effectiveness, Systems theory

Paper type Research paper

\section{The relevance of MBM}

Over the last few years, the complexities confronting organizations have been subject to drastic amplification. As a consequence, the pressure on leaders has markedly increased. Orientation and steering devices have become all the more important, because they enable actors in organizations:

- to find their way in complex settings; and

- to decide and act more effectively and consciously.

This is where high-quality models can make a powerful contribution[1]. To leverage this potential benefit, a research program dedicated to exploring the topic of models and modeling in organizational realities has been designed, which will be outlined in the following sections.

The term Model-based management (MBM) is introduced here to make an important point: the significance of models and modeling to organization and management can hardly be overestimated. This is due to the relatively little reflection given to the use of

The author extends his thanks to Professor José Pérez Ríos and Mr Stefan Groesser for their valuable comments on earlier versions of this paper. 
$\mathrm{K}$

$39,9 / 10$

1420

models in organizations. Such neglect is evident in the fact, first, that the potential of models for enhancing managerial effectiveness and organizational viability is poorly understood and minimally actualized, and, second, that the entire issue has been given too little research attention.

This paper introduces and conceptualizes the idea of MBM as an area of pertinent research. An analysis of the concept, role and function of models in the context of management and organization is undertaken. Furthermore, a research agenda is proposed, in order to stimulate the study necessary for a deeper understanding of this topic that promises to greatly benefit organizations and their members.

\section{Purpose and goals of the research agenda}

The purpose of this research agenda is to improve the state of the art in management theory, but also the modeling and model use in organizations, in order to enhance the intelligence, adaptiveness and viability of organizations of any kind: private, public, non-profit, large or small.

The twin goals of the program are to carry out a general exploration of the field of modeling and to find ways of improving the quality of management models. Both formal and informal models will be objects of research. In the latter case, for example, the process of eliciting a mental model and making it explicit will be studied.

The program should result in a significant contribution to the state of the art of organization and management science. In the first place, it is a matter of theory building, mainly in the sense of empirical research and the science of socio-technical design. However, the theoretical knowledge we are striving for should be applicable at the same time in actual organizations.

\section{Concepts}

By model, we understand the representation of a real system. More exactly, a model is an abstract, conceptual system by which a concrete system is represented.

Models can both reproduce or re-create ( $\rightarrow$ "portrait"), and anticipate ( $\rightarrow$ "paragon"). They may refer to either actual or potential ("ideal") systems, and they can be either formal or informal. A formal model is cast in a stringently logical and mostly mathematical way, e.g. a simulation model, a balance sheet or an architectural plan. Informal models, if explicit, use fuzzier or abridged modes of expression. Often informal models are implicit, e.g. mental models. The term "mental model" refers to models in the minds of actors or observers. In this context, shared mental models are of particular relevance. If they are to be shared, they must be made explicit. In the broad sense of the term, mental models refers to the images, assumptions, theories, concepts, and schemes as well as principles, norms, "philosophies", and world views held by an individual or a collective.

Formal models, then, lend themselves to simulation, by which the behavior of complex, dynamic systems is reproduced in the computer. In this way, experiments can be carried out in order to gain insights into the real system under study.

In view of the topic MBM, we define management, with Ulrich (2001), as the design, (self-) control and development of social systems, organizations in particular. As we shall see, models are crucial devices for any kind of management, be it general management or specific versions of management in the diverse functional areas of organizations. This holds irrespective of organizational type. 
To begin with, modeling in the context of management is about the construction of virtual realities in the minds of observers. The next step is to cast these virtual realities in a formal language. Such formal modeling is of growing importance, as systems become more complex and exhibit counterintuitive behaviors (Forrester, 1971). To get a solid understanding of the structure and behavior of complex, dynamic systems, the support of computer modeling and simulation is indispensable.

\section{The function of models}

Modeling and simulation are devices that help their users to understand the systems they are dealing with. The use of models can fulfill different functions, such as description, explanation, design, decision and change. Descriptive models represent what is the case; they make the issue under study comprehensible. Explanatory models elucidate why the real system at hand behaves as it does and not differently. They try to capture interrelationships, e.g. causalities, interactions and dependencies. Models of analysis and diagnosis, which are among the explanatory models, inquire into the implications of system behavior and of the structure underlying it.

Design models are instruments that support the conceptual development of systems. Decision models, which can be considered a kind of design model, support decision-making processes. They serve the eliciting of options and their comparative assessment, marking the difference between "better" and "worse" variants, mainly by exploring their consequences and implications.

In general, models can trigger the discovery of new perspectives and the gaining of insights. They can support the ascertainment and assessment of options, highlight priorities, illuminate uncertainties, and unveil the dynamic features, propensities, risks, and vulnerabilities of a system. They are very helpful in disciplining the organizational discourse. They are also important in fostering education and learning, in solving problems and in changing conditions or transforming organizations (Pidd, 1996; Schwaninger, 2004; Epstein, 2008). Finally and foremost, "models can surprise us, and lead to new questions" (Epstein, 2008, p. 4).

\section{The importance of models for organizations and management}

The argument that models are important for management has a scientific basis, which can be deduced from a fundamental law of cybernetics - the Conant-Ashby-Theorem. This is a formal, proven law, which in the original says: "Every good regulator of a system must be a model of that system" (Conant and Ashby, 1981). The implication is that the results of any management process cannot be better than the underlying model except by chance. This law has universal validity, because we always manage on the basis of models, whether we want to or not and whether we know it or not. In light of the Conant-Ashby-Theorem, models are a vital prerequisite for organizational viability, and the quest for high-quality models is a must.

This raises the question about the quality of models on the basis of which one makes decisions. It is not enough to build insightful models; they also must be valid. Hence, the first criterion for the quality of a model is validity[2].

Given that modeling is the construction of realities in the minds of observers, validation can serve as both a guarantor for the realism of a model and a control function that prevents gross aberrations in the perceptions of the modeler(s). This double function is of great importance, because strong trends indicate that simulation 
$\mathrm{K}$

$39,9 / 10$

1422 based on formal dynamic models is likely to become ever more important in supporting managers at all levels in decision making and policy design. A model is valid if it represents what it is supposed or claimed to represent. This applies once the constitutive components of the real system under study and the relationships between them are properly captured; in the case of dynamic models, it holds if the behavior of the model over time reflects the behavior of the real system (Schwaninger and Groesser, 2008, 2009). Absolute or timeless validity is an unachievable goal. Models are always surrogates, which are more or less accurate. Therefore, the quality of a model in the context of an organization must be judged, if it fulfills its purpose, as to whether it is better, more appropriate, and more useful than the ones already available. As has been said previously, all models are wrong, but some of them are useful (Sterman, 2000, p. 846, after a famous dictum of George Box). The demand for models of high quality can be expected to increase. Consequently, model validation is likely to become one of the major challenges that lie ahead in modeling and simulation. Validation methodology should contribute greatly to weathering this challenge.

Models have been called "tools for thinking" (Pidd, 1996). The dominant tangible advantage of their use is that they allow experiments in the brain or in the computer. These are normally much less costly and time-consuming than experiments "in the real world". This is of great importance whenever different options must be examined, which is a constant need in the managerial domain.

In conventional terms, modeling is understood as a process by which models are produced. In a wider sense however, modeling can be understood as a vehicle for the creation of new realities. Hence, one may assume that models determine the realities of the future to a high degree. If this assumption holds, then progress in the area of management will substantially hinge on the development of better models. Agents in organizations carry a high responsibility for the quality of the models that determine their decisions and actions. If that quality is neglected, Gresham's law will prevail: the important will be driven out by the trivial and the short-term perspective will supersede long-term orientation.

\section{Types of models}

The diversity of models could be categorized in different ways. In order to avoid a one-dimensional typing, which would be too simplistic, a richer descriptive scheme is used, in which three ideal-types of models are positioned (Figure 1). The dimensions used are:

(1) Depth. Refers to the levels of detail and specificity of a model.

(2) Breadth. Denotes the scope of the domain modeled, between broad and narrow.

(3) Acuity. Indicates the accuracy and precision of a model.

The ideal-types of models discerned, without any claim to be exhaustive, are:

- Frameworks. These are broad schemes which support the orientation within a wide field. A framework offers dimensions and categories, by which a rough overview and a first location, and possibly also a structuring of an issue or problem, can be undertaken. The various generations of the St Gall Management Model are highly condensed frameworks of that kind (Ulrich and Krieg, 1972; Bleicher, 2004; Rüegg-Stürm, 2005). 


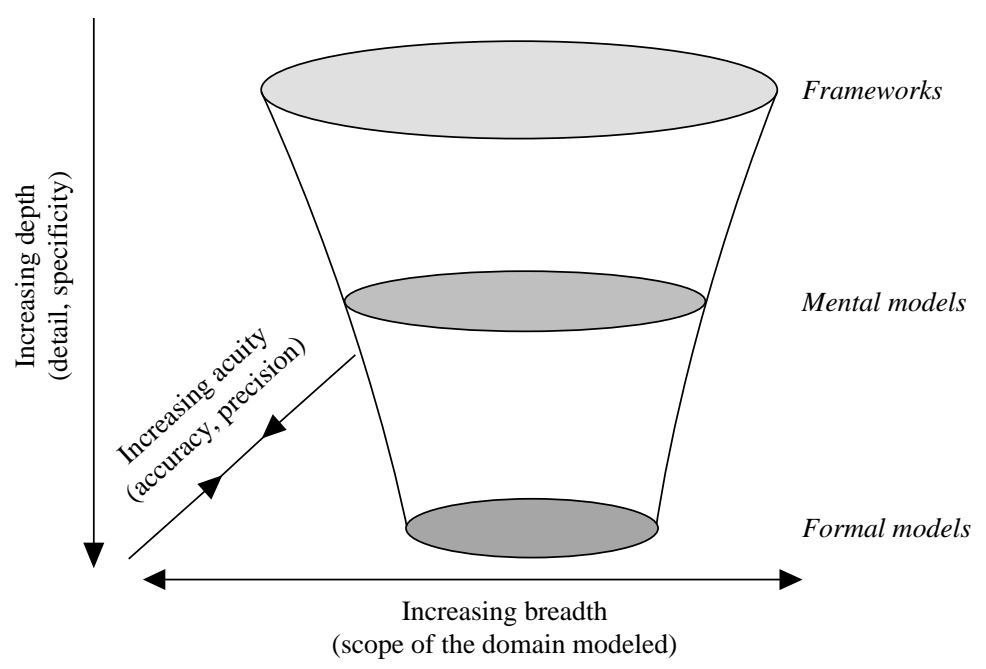

Sources: Contribution to Kybernetes 2010; Schwaninger, model-based management
Model-based management

1423

Figure 1. Ideal-types of models

- Mental models strictu sensu. As distinct from the broad version of the model concept, here we are addressing more specific and accurate models. These are representations of less ample objects, for example in the context of strategic management or organizational issues. Mental models support the determination and discussion of specific causal factors and relationships.

Both frameworks and mental models are conceptual heuristic devices, conceptual meaning that they help in ascertaining and structuring the object under study, and heuristic meaning that they support the finding of solutions, even if the goal has not been defined or the solution is not precise. If we take mental models in a wider sense, including general theories, "philosophies", etc. they might be more encompassing and be placed higher up in the scheme in Figure 1.

- Formal models strictu sensu. At this level, the model is formulated in a stringently logical and normally mathematical language, and it can be calculated algorithmically, i.e. in a defined, finite sequence of steps, within a specified goal system. In the case of a formal model, specificity and precision are further enhanced. At the same time, however, it is necessary to restrict the boundaries of the model.

\section{Axiom}

Much of the debate about strategy has been focused on the competition between firms. But ultimately the competition is between models. The organizations that survive are those with the better models. More generally, the evolution of a social system manifests itself in cultural progress. Such progress is grounded in the evolution of models, which conceptually guides the ongoing process by which socio-cultural reality is shaped. Models are not in the first place objective images of a reality out there, but devices which support the dialogue and the (inter-) action by which: 
$\mathrm{K}$

$39,9 / 10$

1424

- organizations invent and reinvent themselves; and

- desirable futures are created and brought about.

\section{Suggestions for a research program}

In this section, a brief proposal is made concerning the aims, research gap, and research questions for a research program in MBM. Furthermore, some reflections on methodological issues are propounded. Finally, the benefits of such a research program are outlined.

\subsection{Aims of the program}

The program's aim is to develop a methodological basis for the design and use of models in organizations:

- to explore the role of models and modeling in management;

- to examine the impact of models on the process and the result of management;

- to develop principles, rules and procedures for the design of high-quality models and effective modeling processes; and

- to find ways to foster in managers the necessary conceptual understanding for their own development and their use of high-quality models.

In principle, these aims refer to frameworks, mental and formal models, which is to say to both qualitative and quantitative models. Given resource constraints, early on the focus is on formal models. Among the quantitative models, an emphasis will fall on simulation models, which address the complex, often messy problems paramount in organizations.

\subsection{Research gap}

The following research gap should be addressed:

- lack of understanding of the role of formal and mental models in management;

- knowledge deficits concerning how models are developed in organizations;

- minimal insights on the use of formal models and the results achieved with them; and

- little research on how to ensure high-quality models.

While this appraisal cannot be "proved", it can be corroborated, however, by some indicative evidence. First of all, the appraisal is based on many albeit unsystematic observations of managerial practice over many years. Second, a database research we have undertaken hints at a lack of academic discussion around the topic of management models[3]. Third, according to a study carried out among German companies, the interviewees consider modern simulation methods as the number-one success factor in strategy development. However, only less than 5 percent of the responding firms use simulation in the formation and evaluation of strategies, and only 20 percent in strategic analysis (Gilbert et al., 2003). One must add that the above assertion about a research gap meets Popper's criterion of refutability for scientific propositions, as it could, in principle, be refuted on empirical grounds[4]. 


\subsection{Research questions}

The following list of research questions is non-exhaustive, because further and more specific issues will emerge in the research process:

RQ1. How can both management and organizations be improved by means of models?

$R Q 2$. Do strategy makers use formal models?

RQ3. Does the use of formal models make a difference?

RQ4. How should formal models be designed for higher managerial effectiveness?

RQ5. How can mental models be validated and improved?

\subsection{Methodology}

The research in this program should be grounded in system theory and cybernetics, because these are the sciences that focus on complexity and holistic system design. Other disciplines, e.g. organization science, psychology, sociology and cognitive science, will contribute as well to the study of MBM.

Given the complexity and large scope of the topic, different methods will be needed for the realization of the research activities. In the following list (Table I), a number of more specific research questions than those just listed is related to different methods and rules that can be used. This list is offered without any claim to completeness.

Some of the research into these topics can already be related to a substantial body of empirical research. For example, valuable insights concerning the design of model-based decision processes, learning laboratories and simulation environments, along with a wealth of studies on interactive learning environments and dynamic decision making, have already been accumulated[5].

\begin{tabular}{ll}
\hline Method & Research questions \\
\hline Survey & What kinds of models are used? \\
& For what purpose are they used? \\
What are the effects of model use? & How are models used? \\
Case study & Which features of modeling processes lead to high-quality models? \\
Experiment & How can models be customized to specific contexts? \\
& How do distinct approaches to model use differ in their effect on \\
& performance? \\
& Which factors determine the efficacy of model use? \\
Design principles and tests & How should models be designed to improve performance? \\
& How can models support organizational processes for effective \\
& decisions and actions? \\
& How should modeling processes be designed for high-quality models \\
& to emerge? \\
& How can learning with models be enhanced? \\
& How should decisional aids (e.g. feedback, decision heuristics, and \\
human facilitation) and human-computer-interfaces, both of which \\
complement models, be designed?
\end{tabular}


$\mathrm{K}$

$39,9 / 10$

\section{6}

8.5 Benefits

The following list relates to the expected ultimate benefits for model-users and their organizations:

- higher intelligence and viability of organizations;

- availability of design methods for high-quality (more accurate, valid, fruitful, etc.) models;

- knowledge for more effective and efficient modeling and model validation processes;

- clarity about methodological choices;

- higher managerial effectiveness for model users; and

- enhancement of the quality of organizations (economic, human-social, socio-technical and ecological).

\section{Outlook}

The work presented here is meant to contribute to the design, (self-)control and development of organizations so that they can attain higher intelligence, adaptiveness and viability.

A crucial challenge for the proposed research endeavor is to provide ways to design better models - including theories, frameworks[6], etc. - which are more apt to enhance the capability of organizations to master the paramount and growing complexities (and contingencies) which they face, and to cope in adaptive and responsive modes.

The research program laid out here, even in its relatively crude form, can make a substantial contribution to the quality and impact of models in all kinds of enterprises. It will generate new knowledge that is vital for organizations. Given the demanding goals of the program, cooperation beyond the boundaries of any single institution will be indicated.

\section{Notes}

1. Inadequate models, on the other hand, can inflict great damage on organizations, as has been the case lately in financial institutions (Mollenkamp et al., 2008).

2. Other factors of model quality are, e.g. relevance, accuracy, comprehensiveness, fruitfulness, and practicality.

3. A search in the JSTOR database, carried out on September 18, 2008, produced the following result: keywords "Management AND Model" in article titles: 133 hits. These went back as far as 1964 and included such diverse topics as manpower management, balance sheet management, fuel management, decision support, land management and forest management. Only one title referred to an empirical test of model use (Chung et al., 2000). All the other papers were focused on the description of a variety of models, methods and tools. Keywords "Management AND Management AND Use" in article titles: two hits, both of them not applicable to a general view on management models. Keywords "Management AND Management AND Use" in abstracts: 15 hits, of little utility in the context of a general management view of models. Furthermore, in a search on September 17, 2008, in the Amazon.com database, with the search criterion "Management AND Model", the first 100 hits showed only seven books having these terms in their titles. Most of these were specialized, e.g. tied to a product management model, linear programming, etc.

4. This is a reference to the falsification principle (Popper, 1959). 
5. For an overview, see Karakul and Qudrat-Ullah (2008) and literature referred therein.

6. A framework for the design and development of intelligent organizations has been proposed in Schwaninger (2009).

\section{References}

Bleicher, K. (2004), Das Konzept. Integriertes Management, 7th ed., Campus, Frankfurt.

Chung, Q.B., Willemain, T.R. and O'Keefe, R.M. (2000), "Influence of model management systems on decision making: empirical evidence and implications", Journal of the Operations Research Society, Vol. 51, pp. 936-48.

Conant, R.C. and Ashby, W.R. (1981), "Every good regulator of a system must be a model of that system", in Conant, R.C. (Ed.), Mechanisms of Intelligence: Ross Ashby's Writings on Cybernetics, Intersystems Publications, Seaside, CA, pp. 205-14 (originally published in 1970, International Journal of System Science, Vol. 1 No. 2, pp. 89-97).

Epstein, J.M. (2008), “Why model?”, Working Paper SFI-WP 08-09-040, Santa Fe Institute, Santa Fe.

Forrester, J.W. (1971), “Counterintuitive behavior of social systems”, Technology Review, Vol. 73 No. 3, pp. 52-68.

Gilbert, D.U., Behnam, M. and Luber, T. (2003), "Wichtige Erfolgspotenziale liegen in deutschen Unternehmen brach", Absatzwirtschaft Online, February.

Karakul, M. and Qudrat-Ullah, H. (2008), "How to improve dynamic decision making? Practice and promise", in Qudrat-Ullah, H., Spector, J.M. and Davidsen, P.I. (Eds), Complex Decision Making: Theory and Practice, Springer, Berlin, pp. 3-24.

Mollenkamp, C., Ng, S. and Pleven, L. (2008), "Computer liessen die AIG untergehen”, Handelszeitung, November 12-18, p. 38.

Pidd, M. (1996), Tools for Thinking: Modelling in Management Science, Wiley, Chichester.

Popper, K.R. (1959), The Logic of Scientific Discovery, Basic Books, New York, NY (latest edition: 2002, Routledge, London).

Rüegg-Stürm, J. (2005), The New St Gallen Management Model: Basic Categories of an Approach to Integrated Management, Palgrave Macmillan, Basingstoke (original version in German: Rüegg-Stürm, J. (2002). Das neue St Galler Management-Modell, Paul Haupt Verlag, Bern).

Schwaninger, M. (2004), "Was ist ein Modell?”, in Dubs, R., Euler, D., Rüegg-Stürm, J. and Wyss, C. (Eds), Einführung in die Managementlehre, Haupt, Bern.

Schwaninger, M. (2009), Intelligent Organizations: Powerful Models for Systemic Management, 2nd ed., Springer, Berlin.

Schwaninger, M. and Groesser, S.N. (2008), "Model-based theory-building with system dynamics", Systems Research and Behavioral Science, Vol. 4, pp. 447-65.

Schwaninger, M. and Groesser, S.N. (2009), "System dynamics modeling: validation for quality assurance”, in Meyers, R.A. (Ed.), Encyclopedia for Complexity and Systems Science, Vol. 9, Springer, New York, NY, pp. 9000-14.

Sterman, J.D. (2000), Business Dynamics. Systems Thinking and Modeling for a Complex World, Irwing/McGraw-Hill, Boston, MA.

Ulrich, H. (2001), Gesammelte Schriften, Paul Haupt, Bern.

Ulrich, H. and Krieg, W. (1972), St Galler Management-Modell, Paul Haupt, Bern. 
$\mathrm{K}$

$39,9 / 10$

1428

\section{About the author}

Markus Schwaninger is a Professor of Management at the University of St Gallen, Switzerland. His research is focused on the study of complex socio-technical systems, with a methodological focus on organizational cybernetics and system dynamics. His research projects to date have been related to organizational intelligence, the design, transformation and learning of organizations, and to systemic issues of sustainability. Markus Schwaninger is the author of roughly 200 publications in six languages, including Organizational Transformation and Learning (Wiley, 1996; with Espejo and Schuhmann), and Intelligent Organizations (Springer, Second Edition, 2009). He has lectured widely, on four continents, and is involved in international, transdisciplinary research projects. Markus Schwaninger can be contacted at: markus.schwaninger@unisg.ch

To purchase reprints of this article please e-mail: reprints@emeraldinsight.com Or visit our web site for further details: www.emeraldinsight.com/reprints 